Buletin Peternakan Tropis

Bulletin of Tropical Animal Science

Doi: https://doi.org/10.31186/bpt.2.2.125-129
Bul. Pet. Trop. 2(2): 125-129, 2021

e-ISSN: $2722-0788$

p-ISSN: $2722-1733$

\title{
Evaluasi Penggunaan Etanol dan Surfaktan Tween 80 dalam Melarutkan Vitamin E pada Bahan Pengencer Sperma Andromed
}

\author{
(Comparative Evaluation of Ethanol and Surfactant Tween 80 to Dissolve Vitamin E in Andromed \\ Semen EXtender) \\ Labib Abdillah ${ }^{1,2}$, Sigit Bintara ${ }^{2}$, Dyah Maharani², I Gede Suparta Budisatria ${ }^{2}$ \\ ${ }^{1}$ department of animal science, faculty of agriculture, Tidar University: jalan kapten suparman no.39 Magelang, \\ Indonesia 56116 \\ ${ }^{2}$ faculty of animal science, universitas gadjah mada: jalan fauna no. 3 bulaksumur, Yogyakarta, Indonesia 55281 \\ * Penulis Korespondensi (labibabdillah@untidar.ac.id)
}

Dikirim (received): 27 Oktober 2021; dinyatakan diterima (accepted): 31 Oktober 2021; terbit (published): 15 November 2021. Artikel ini dipublikasi secara daring pada https://ejournal.unib.ac.id/index.php/buletin_pt/index

\section{ABSTRACT}

The aim of this study was to measured bioavailability of vitamin E. Vitamin E was dissolved using different solvents. Both, surfactant tween 80 and ethanol are used as solvent in the Andromed semen extender. The Treatment given in this study were antioxidant vitamin $\mathrm{E}$ and oil solvent. Treatment were divided into five groups, Andromed control (PO), Andromed Vit E (0.2 gr) + ethanol (P1), Andromed vit.E ( $0.2 \mathrm{gr})$ + tween 80 ( P2), Andromed vit. E (0.4 g) + ethanol (P3) and Andromed Vit. E (0.4 g) + tween 80 (P4). This research used an experimental approach and analyzed using descriptive method. The mixture of vitamin $E$ with solvent according to the treatment referred as vitamin E preparation. The vitamin E preparation was mixed into Andromed extender. The extender samples were analyzed using DPPH analysis to measure the antioxidant activity of vitamin $\mathrm{E}$. The results of this study showed the highest antioxidant activity obtained in combination of Vit. E with tween 80 (91.29\%). The combination of Vitamin E with ethanol only reach $57.45 \%$, and the lowest was in the control extender without the addition of vitamin E. Tween 80 as a vitamin E solvent had a better ability to dissolve vitamin E into semen extender than ethanol.

Key words: Andromed, Antioxidant activity, Ethanol, Tween 80, Vitamin E

\section{ABSTRAK}

Penelitian ini dirancang untuk menguji bioavailabilitas vitamin $\mathrm{E}$ yang dilarutkan dengan menggunakan pelarut yang berbeda, yaitu surfaktan tween 80 dan etanol pada bahan pengencer semen Andromed. Perlakuan yang diberikan pada penelitian ini adalah bahan antioksidan vitamin $\mathrm{E}$ dan bahan pelarut minyak yang terbagi dalam kelompok Andromed kontrol (P0), Andromed Vit E (0.2 gr) + etanol (P1), Andromed vit. E (0.2 gr) + tween 80 (P2), Andromed vit. E (0.4 gr) + etanol (P3) dan Andromed Vit. E (0.4 $\mathrm{gr})+$ tween 80 (P4). Metode penelitian menggunakan pendekatan eksperimental, dan dianalisis secara deskriptif. Vitamin E dikombinasikan dengan pelarut sesuai perlakuan yang selanjutnya disebut sediaan vitamin E. Sediaan vitamin E kemudian dicampurkan kedalam bahan pengencer. Sampel bahan pengencer tersebut dianalisis menggunakan analisis DPPH untuk mengukur aktivitas dari vitamin $\mathrm{E}$ di dalam bahan pengencer semen. Hasil penelitian menunjukkan nilai aktivitas antioksidan bahan pengencer yang diberikan kombinasi Vit. E dan tween 80 paling tinggi sebesar $91.29 \%$ sedangkan bahan pengencer dengan kombinasi Vit. E dan etanol aktivitas antioksidan tertingginya sebesar $57.45 \%$ dan hasil paling rendah pada bahan pengencer control tanpa penambahan vitamin E. Tween 80 sebagai pelarut vitamin $\mathrm{E}$ memiliki kemampuan yang lebih baik dalam melarutkan vitamin $\mathrm{E}$ dalam bahan pengencer semen jika dibandingkan dengan etanol.

Kata kunci: Aktivitas antioksidan, Andromed, Etanol, Tween 80, vitamin E 


\section{PENDAHULUAN}

Program IB akan berjalan dengan baik apabila didukung dengan produksi sperma yang berjalan dengan baik dari segi kualitas maupun kuantitasnya. Untuk mendukung hal tersebut, perbaikan kualitas bahan pengencer merupakan salah satu faktor yang harus dilakukan. Bahan pengencer merupakan suatu larutan yang mengandung berbagai nutrisi yang esensial bagi sel spermatozoa selama proses pengolahan menjadi semen cair maupun semen beku. Kandungan nutrisi yang terdapat didalam bahan pengencer dapat teroksidasi akibat penyimpanan dan pengolahan. Hal tersebut mengakibatkan peningkatan radikal bebas didalam bahan pengencer (Winangun, 2019). Radikal bebas yang terakumulasi dalam bahan pengencer dapat mempengaruhi kualitas semen pada saat pengolahan. Reaksi ini dapat dihambat dengan penambahan antioksidan (Gangwar et al., 2015).

Berbagai bahan pengencer telah banyak digunakan sampai dengan saat ini, baik bahan pengencer konvensional sampai bahan pengencer komersial. Salah satu bahan pengencer komersial yang umum digunakan dalam pengenceran semen adalah Andromed. Bahan pengencer ini belum mengandung antioksidan didalamnya. Andromed merupakan bahan pengencer komersial terdiri dari fosfolipid, tris- (hidroksimetil)aminometan, asam sitrat, fruktosa, gliserol, tilosin tartrat, gentamisin sulfat, spektinomisin, dan linkomisin (Minitub, 2001).

Salah satu antioksidan yang dapat digunakan dalam bahan pengencer sperma adalah vitamin $E$, penggunaan vitamin $E$ didasarkan bahwa pada plasma semen terkandung vitamin E (Moretti et al., 2011). Pengaruh proyektif vitamin E erat kaitannya dengan daerah yang dekat dengan fosfolipid di dalam membran sel, sehingga efisiensi penambahan vitamin $E$ sangat tergantung jumlah vitamin $E$ yang diakumulasikan di dalam membran plasma spermatozoa (Breininger et al., 2005).
Vitamin E merupakan vitamin yang bersifat hydrophobic atau larut didalam lemak sehingga memiliki keterbatasan kelarutan dalam medium air (Benhenia et al., 2016). Penggunaannya dalam bahan pengencer tidak dapat dicampurkan secara langsung, hal ini karena penggunaan andromed sebagai pengencer dikombinasikan dengan larutan $\mathrm{NaCl}$ atau aquabidest dengan perbandingan 1:4 (Herold et al.,2006).

Umumnya sebelum dilarutkan dalam bahan pengencer spermatozoa, vitamin $E$ dilarutkan dalam etanol dengan perbandingan 1:5 (Herdis et al.,2002). Penggunaan alkohol sebagai co-surfactant dapat menyebabkan toksik dan iritasi (Flanagan dan Singh, 2006), selain itu etanol merupakan bahan semi polar (Jusnita, 2014). Peneliti lainnya menyebutkan bahwa penambahan bahan pengemulsi terbukti dapat mengefektifkan penggunaan vitamin E (Mocé et al., 2010). tween 80 merupakan surfaktan non ionic dan tidak bersifat toksik serta sangat efisien dalam membentuk droplet kecil vitamin $E$ pada konsentrasi kecil (Yang et al., 2013). Penelitian ini dilakukan untuk mengukur kemampuan etanol dan tween 80 untuk meningkatkan bioavailabilitas vitamin $E$ dalam bahan pengencer semen.

\section{BAHAN DAN METODE}

Waktu dan tempat

Penelitian ini dilaksanakan dalam rentang waktu Juli sampai dengan Oktober 2017. Penelitian ini dilakukan di Laboratorium Fisiologi Reproduksi Fakultas Peternakan Universitas Gadjah Mada. Analisis sampel dilakukan di Laboratorium Uji Teknologi Pangan dan Hasil Pertanian Fakultas Teknologi Pertanian Universitas Gadjah Mada.

\section{Alat dan Bahan}

Alat yang digunakan dalam penelitian diantaranya adalah Vortex untuk membuat sediaan vitamin $E$, spectrophotometer untuk menganalisis aktivitas antioksidan. Bahan 
yang digunakan antara lain bahan pengencer Andromed dan vitamin $\mathrm{E}$.

\section{Metode penelitian dan Analisis data}

Penelitian ini dilakukan secara eksperimental dan dianalisis secara deskriptif. Bahan pengencer disiapkan dengan melarutkan Andromed dengan Aquabidest dengan perbandingan $1: 4$. Sediaan vitamin $E$ dibuat dengan melarutkan vitamin $\mathrm{E}$ kedalam bahan pelarut etanol (1:5) dan tween 80 (1:5). Sampel bahan pengencer Andromed kemudian ditambahkan dengan vitamin $E$ sesuai perlakuan sehingga didapatkan perlakuan yaitu Andromed control (PO), Andromed Vitamin E $0.2 \mathrm{gr}+$ etanol (P1), Andromed vitamin E (0.2 gr) + tween 80 (P2), Andromed vitamin E (0.4 gr) + etanol (P3) dan Andromed vitamin E (0.4 gr) + tween 80 (P4). Kemudian campuran dihomogenkan menggunakan Vortex selama 1 menit.

\section{HASIL DAN PEMBAHASAN}

Uji aktivitas antioksidan dilakukan pada sampel bahan pengencer semen. Uji ini bertujuan untuk mengetahui keberadaan senyawa yang berperan sebagai antioksidan. Uji ini dilakukan dengan prinsip reaksi antara radikal bebas DPPH dengan senyawa antioksidan. Senyawa antioksidan akan mengubah warna radikal bebas DPPH dari warna violet menjadi warna kuning. Hal ini terjadi akibat kemampuan dalam mengikat elektron bebas yang tidak berpasangan dari senyawa radikal. Gambar 1 menunjukkan bahwa nilai aktivitas antioksidan tertinggi diperoleh pada perlakuan P4 disusul P2, P3 dan $\mathrm{P} 1$ serta yang paling rendah adalah $\mathrm{P} 0$.

Perlakuan kombinasi vitamin $E$ dengan tween 80 menghasilkan bioavailabilitas vitamin $\mathrm{E}$ dalam bahan pengencer yang lebih tinggi. Upaya meningkatkan bioavailabilitas dengan menambahkan tween 80 cukup berhasil, hal ini terlihat pada hasil uji analisis aktivitas antioksidan pada perlakuan P2 dan P4 yang lebih tinggi dibandingkan dengan perlakuan P1 dan P3.
Keterbatasan bioavailabilitas vitamin E dalam air sudah disampaikan beberapa peneliti sebelumnya, seperti dijelaskan oleh Saberi et al (2013) bahwa vitamin E merupakan bahan yang sangat rendah kelarutannya dalam air dan bioavailabilitasnya sangat bervariasi sehingga membutuhkan bahan pengemulsi untuk meningkatkan bioavailabilitasnya. Dilanjutkan juga bahwa bahan pengencer yang dilarutkan dalam aquabidest menjadi faktor yang mempengaruhi kelarutan vitamin $E$ karena vitamin E kurang efisien penggunaannya pada lingkungan yang hidrofilik (Azawi \& Hussein, 2013).

Gambar 1. Hasil analisis aktivitas antioksidan sampel bahan pengencer

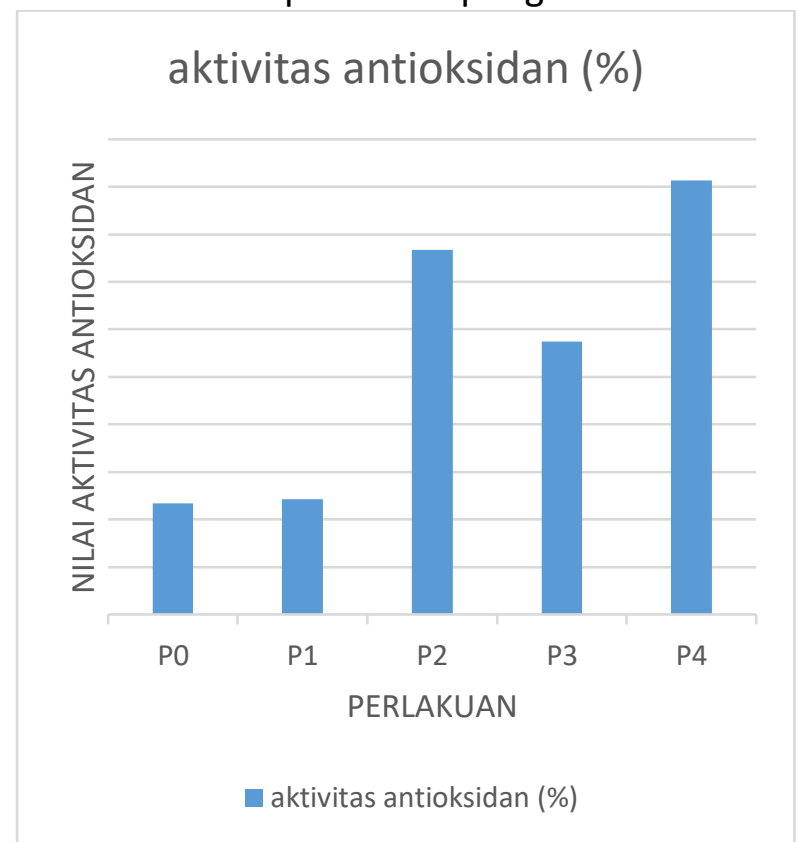

Peningkatan kelarutan vitamin E pada perlakuan P2 dan P4 disebabkan karena vitamin $\mathrm{E}$ diubah menjadi bentuk droplet kecil oleh tween 80. Tween 80 bekerja dengan membentuk droplet kecil vitamin E dalam medium air (Yang et al., 2013). Hasil yang sama juga diperoleh Benhenia et al (2016) menyebutkan bahwa vitamin $E$ dapat ditingkatkan kelarutannya dengan penambahan bahan pengemulsi. Hasil penelitian juga menunjukkan bahwa perlakuan P1 dan P4 memiliki aktivitas 
antioksidan yang lebih tinggi dibandingkan perlakuan kontrol. Hal ini dimungkinkan karena etanol mampu melarutkan sebagian kecil dari vitamin E yang diberikan. Dubbs dan Gupta (1998) menyatakan bahwa vitamin E memiliki rantai alkana hidrofobik yang besar sehingga tingkat kelarutannya di dalam air sangat rendah. Namun dengan penambahan etanol dalam air dapat membantu kelarutan dari vitamin E. Saberi et al. (2013) menyatakan bahwa etanol memberikan stabilitas karena sebagian tercampur dalam fasa air dan minyak sehingga mengurangi tegangan antar muka antara air dan minyak. Namun, keefektifannya kurang karena etanol adalah bahan yang mudah sekali untuk menguap. Selain itu etanol merupakan bahan semi polar (Jusnita, 2014) dan merupakan golongan co-surfaktan yang fungsinya membantu surfaktan dalam mengemulsikan minyak dalam air (Setya et al., 2014).

\section{KESIMPULAN}

Berdasarkan hasil penelitian yang dilakukan dapat disimpulkan bahwa bioavailabilitas vitamin E dalam bahan pengencer Andromed dapat ditingkatkan dengan menggunakan tween 80. Penggunaan tween 80 dapat menggantikan etanol dalam meningkatkan kelarutan vitamin $\mathrm{E}$ dalam bahan pengencer semen.

\section{Ucapan Terimakasih}

Ucapan terimakasih penulis sampaikan kepada Laboratorium Fisiologi Reproduksi dan Laboratorium Genetika dan Pemuliaan Fakultas Peternakan Universitas Gadjah Mada karena telah mendukung terlaksananya penelitian ini.

\section{DAFTAR PUSTAKA}

Azawi, O. I., Hussein, E. K. 2013. Effect of vitamins $C$ or $E$ supplementation to tris diluent on the semen quality of awassi rams preserved at $5^{\circ} \mathrm{C}$. Vet Res Forum. 4: 157160.
Benhenia, K., Lamara, A., Fatmi, S., IguerOuada, M. 2016. Effect of cyclodextrins, cholesterol and vitamin $E$ and their complexation on cryopreserved epididymal ram semen. Small Rum Res. 141: 29-35. DOI: 10.1016/j.smallrumres.2016.06.009

Breininger, E., Beorlegui, N. B., O'Flaherty, C. M., \& Beconi, M. T. 2005. Alpha-tocopherol improves biochemical and dynamic parameters in cryopreserved boar semen. Theriogenology. 63: 2126-2135. DOI: 10.1016/j.theriogenology.2004.08.016

Dubbs, M. D. Dan Gupta, R. B. 1998. Solubility of vitamin e ( $\alpha$-tocopherol) and vitamin $\mathrm{K} 3$ (Menadione) in ethanol-water mixture. Journal of Chemical and Engineering Data. 43(4): 590 591. DOI: 10.1021/je980017।

Flanagan, J., and Singh, H. 2006. Microemulsions; a potential delivery system for bioactives in food. Food Science and Nutrition. 46: 221- 237. DOI: 10.1080/10408690590956710

Gangwar, C., Kharche, S. D., Ranjan, R., Kumar, S., Goel, A. K., Jindal, S. K., \& Agarwal, S. K. 2015. Effect of vitamin $C$ supplementation on freezability of Barbari buck semen. Small Rum Res. 129: 104-107. DOI: 10.1016/j.smallrumres.2015.06.002

Herdis, Kusuma, I., Surachman, M., Riza, M., Sutama, I.K., Inounu, I., Arifiantini, I. 2002. Peningkatan Kualitas semen beku domba garut melalui penambahan $\alpha$-Tokoferol ke dalam pengencer susu-skim kuning telur. Jurnal Ilmu Ternak dan Veteriner. 7: 12-17. DOI: 10.14334/jitv.v7i1.269

Herold, F. C., de Haas, K., Colenbrander, B., Gerber, D. 2006. Comparison of equilibration times when freezing epididymal sperm from African buffalo (Syncerus caffer) using Triladyl or AndroMed. Theriogenology. 66: 11231130. DOI:

10.1016/j.theriogenology.2006.03.007 Jusnita, N. 2014. Produksi Nanoemulsi Ekstrak Temulawak Dengan Metode Homogenisasi. Tesis, Institut Pertanian Bogor, Bogor. 
Minitub. 2001. Certificate Andromed. Minitub Abfullund Labortechnik GmbH and Co KG, Germany.

Mocé, E., Purdy, P. H., Graham, J. K. 2010. Treating ram sperm with cholesterolloaded cyclodextrins improves cryosurvival. Anim Reprod Sci. 118: 236-247. DOI: 10.1016/j.anireprosci.2009.06.013

Moretti, E., Castellini, C., Mourvaki, E., Capitani, S., Geminiani, M., Renieri, T., Collodel, G. 2011. Distribution of $\alpha$ - and $\delta$ tocopherols in seminal plasma and sperm fractions of men with normal and abnormal semen parameters. J Androl. 32: 232-9. DOI: 10.2164/jandrol.109.009936

Saberi, A. H., Fang, Y., Mcclements, D.J. 2013. Fabrication of vitamin $\mathrm{E}$ - enriched nanoemulsions by spontaneous emulsification: effect of propylene glycol and ethanol on formation, stability, and properties. Food Research International. 54; 812-820. DOI: 10.1016/j.foodres.2013.08.028

Setya, S., Talegaonkar, S., Razdan, B. K. 2014. Nanoemulsions:Formulation methods and stability aspects. World Journal of Pharmacy and Pharmaceutical Sciences. 3: 2214-2228.

Winangun, K. 2019. Kualitas Larutan Pengencer Dan Kualitas Semen Domba Pada Temperatur Penyimpanan Yang Berbeda. Kandaga-Media Publikasi IImiah Jabatan Fungsional Tenaga Kependidikan, 1(1). DOI: 10.24198/kandaga.v1i1.21217

Yang, Y., Julian, D., Clements, M. 2013. Encapsulation of vitamin $E$ in edible emulsions fabricated using a natural surfactant. Food Hydrocolloids. 30: 712720. DOI: 10.1016/j.foodhyd.2012.09.003 